\title{
Análise epistemológica das teses e dissertações sobre atendimento educacional especializado: 2000 a 2009
}

\author{
Rosana Castro Casagrande* \\ Gilmar de Carvalho Cruz**
}

\section{Resumo}

O objetivo geral desta pesquisa foi realizar uma análise epistemológica de teses e dissertações sobre atendimento educacional especializado produzidas no período de 2000 a 2009, a partir das dimensões técnica e teórica, analisadas através da adaptação do Esquema Paradigmático de Sánchez Gamboa (1987; 2007). Por meio de uma pesquisa qualitativa, foi realizada análise documental de 18 teses e dissertações. Os resultados indicam: l. No Nível Técnico: Em 2009 foi o período que mais se produziu pesquisas sobre AEE; $72 \%$ do total foram produzidas em Universidades Públicas; 44\% não especificaram as técnicas de registro; $50 \%$ não especificaram o tipo de análise de dados; $84 \%$ apresentaram procedimentos qualitativos; 2. Nível Teórico: Os principais temas tratados foram "Deficiência Auditiva/Surdez" (27,7\%); 61\% apresentaram abordagens metodológicas e tipos de mudança do tipo Inespecífica; $17 \%$ caracterizaram-se como crítico-dialéticas e 22\% fenomenológico-hermenêuticas. A maioria das pesquisas não pode ser caracterizada ou classificada segundo um padrão de abordagem metodológica, devido ao seu aspecto hibrido e ao fato de não apresentar uma fronteira metodológica. É fundamental que sejam ampliadas as pesquisas sobre análise epistemológica, a fim de contribuírem de forma significativa e efetiva para a melhoria na qualidade das pesquisas e para sua aproximação com a práxis.

Palavras-chave: Educação especial; Atendimento Educacional Especializado; Epistemologia.

\footnotetext{
* Docente do Departamento de Métodos de Ensino - Universidade Estadual de Ponta Grossa (UEPG), Ponta Grossa, Paraná, Brasil.

** Pós-Doutor pela Universidade do Estado do Rio de Janeiro. Docente adjunto da Universidade Estadual do Centro-Oeste e docente permanente do programa de Mestrado e Doutorado em Educação da Universidade Estadual de Ponta Grossa. Ponta Grossa, Paraná, Brasil.
} 


\section{Epistemological analysis of theses and dissertations on special education service: 2000 to 2009}

\section{Abstract}

The general aim of this research was to carry out an epistemological analysis of theses and dissertations on special education service written between 2000 and 2009. The analysis is based on the technical and theoretical dimensions and it uses an adaptation of the Paradigmatic Scheme by Sánchez Gamboa $(1987,2007)$. Following a qualitative approach, the documentary analysis of 18 theses and dissertations was carried out. The results indicate: 1. At the Technical Level: 2009 was the most prolific year for research on special education service; $72 \%$ of all the works were produced in public universities; $44 \%$ do not specify the recording techniques; $50 \%$ do not specify the type of data analysis; $84 \%$ present qualitative procedures; 2 . Theoretical Level: the main tackled theme was "Hearing Impairment/Deafness" (27.7\%); $61 \%$ made use of unspecific methodological approaches and types of changes; $17 \%$ are classified as critical and dialectical, and 22\% are phenomenological and hermeneutic. Most of the works could not be characterized or classified according to a standard methodological approach in view of their hybrid aspect and due the fact that they do not have a methodological boundary. It is essential to extend research on epistemological analysis so that it can effectively contribute to improving studies and directing them towards praxis.

Keywords: Special education; Special education service; Epistemology.

Somente, a partir da década de 1970, e, especialmente em 1988, com a promulgação da Constituição Federativa do Brasil, que os debates acerca da educação especial foram se intensificando. Em 1994, a Declaração de Salamanca, juntamente com outros documentos internacionais e nacionais, veio a suscitar o que presenciamos até os dias de hoje: os debates e embates em torno da Educação Especial e, consequentemente, do atendimento educacional especializado. Foi também na década de 1970, que se estruturavam os primeiros Cursos de Pós-Graduação no Brasil e o momento em que se desenvolviam as pesquisas em educação especial, levantando temas que retratavam o contexto politico, social e educacional das pessoas com necessidades especiais.

Na década de 1990, intensifica-se "a discussão em torno dos modelos de pesquisa e sobre o conflito entre os paradigmas científicos" (SÁNCHEZ GAMBOA, 2007, p. 48). No Brasil, a preocupação com as produções científicas em educação especial, no tocante a sua análise epistemológica, pode ser considerada recente, por isso pudemos notar a escassez de trabalhos referentes a esse tipo de análise.

Nesse contexto, consideramos que a educação especial e o atendimento educacional especializado carecem de perspectivas de análise epistemológica. A 
ampliação no número de pesquisas, a diversificação dos temas e na metodologia são alguns indicativos de que as pesquisas em educação especial vêm delineando um caminho promissor. Mas, para que esse caminho seja efetivamente reconhecido como promissor, é importante considerar o caráter epistemológico que se constitui numa perspectiva crítica em torno da construção desse conhecimento.

\section{Pesquisa em educação especial e atendimento educacional especializado: um trecho do percurso}

Os trabalhos direcionados à produção científica em educação especial são considerados recentes, "desde os anos 1980, quando pesquisadores desse campo começaram a avaliar os estudos produzidos, até os dias atuais, várias pesquisas foram desenvolvidas na perspectiva de avaliar o conhecimento produzido pela área" (HAYASHI, 2011, p. 147).

Em relação à questão epistemológica da pesquisa educacional, o trabalho de Sánchez Gamboa (1987) traz uma contribuição significativa ao analisar 502 dissertações e teses produzidas pelos cursos de pós-graduação no Estado de São Paulo. O autor identificou várias vertentes epistemológicas, das quais classificou e categorizou três grupos, bem como sua ocorrência: pesquisas de abordagem empírico-analítica (66\%), pesquisas de abordagem fenomenológico-hermenêutica (22,5\%) e as de abordagem crítico-dialética (9,5\%). Nesse sentido, destaca-se a pesquisa realizada no período final da década de 1990 até a metade do ano de 2000 e desenvolvida, em quatro etapas, por um grupo de pesquisadores da Universidade Federal de São Carlos - UFSCar; Universidade Estadual do Rio de Janeiro - UERJ e Universidade Metodista de Piracicaba - UNIMEP, onde analisaram as dissertações e teses dos programas de Pós-Graduação em Educação e Psicologia, no período de 1974 a 2004 (HAYASHI, 2011).

Em relação a pesquisas sobre atendimento educacional especializado, estudos da última década sugerem avanço na compreensão da importância em desenvolver pesquisas envolvendo esse tema: Magalhães (2006); Silva (2008); Chiesa (2009); Araóz (2009); Queiroz Junior (2010); Dias (2010) e Silva (2010).

Além da expansão das pesquisas, da diversificação dos temas, das mudanças nas abordagens e instrumentos, é importante considerar que as pesquisas em educação especial e atendimento educacional especializado devem considerar os aspectos epistemológicos na realização de suas pesquisas, de modo a buscarem maior lucidez teórico-prática e possibilidade de transformação. O termo transformação social, aqui destacado, não deve ser tomado de forma romântica, mas como uma prática possível na medida em que consideramos que as pesquisas devem visar à contribuição social ou que, ao menos, possibilitem uma transformação, seja ela do sujeito ou do ambiente onde este sujeito atua. As publicações das produções científicas podem ser consideradas, nesse contexto, uma forma de contribuição para transformação social, na medida em que permitem a transformação: do sujeito que pesquisa; dos sujeitos que participaram do processo da pesquisa, e dos sujeitos que leem as publicações. 


\section{Metodologia}

A presente pesquisa caracteriza-se como quanti-qualitativa. A porcentagem foi utilizada como estimador. Utilizamos, como técnica para abordar os dados qualitativos, a análise documental.

Lüdke e André (1986, p. 38) a consideram "uma técnica valiosa de abordagem de dados qualitativos, seja complementando as informações obtidas por outras técnicas, seja desvelando aspectos novos de um tema ou problema". Esse trabalho sustenta-se na concepção de pesquisa qualitativa defendida por Sánchez Gamboa (2003, p. 395), o qual considera que "as diferentes formas de fazer ciência não se esgotam na alternativa quantitativista ou qualitativista". Também se caracteriza pela utilização de recursos de categorização na análise do aspecto teórico e, para tal, recorremos a Bardin (2009) que explica que a Análise de Conteúdo (AC) constitui-se em uma das técnicas relativas à inferências de dados em um determinado contexto, envolvendo procedimentos específicos para processamento de dados de modo científico.

\section{Campo e critérios de coleta de dados da pesquisa}

O campo de pesquisa foi o site da CAPES http://www.capes.gov.br e, foram estabelecidos seis critérios para coleta dos dados. Acesso ao portal da CAPES Serviços - Banco de Teses - Resumos;

Critério l - No portal banco de teses 〈http://capesdw.capes.gov.br/capesdw>, foi digitado no campo Assunto: Atendimento Educacional Especializado, o qual apresentou como resultado um total de 112 dissertações e teses;

Critério 2 - Foram elencadas as dissertações e teses publicadas no período de 2000 a 2009, a fim de analisar a última década de produção na área, considerada como sendo mais recente;

Critério 3 - Foram selecionadas as dissertações e teses do período de 2000 a 2009 cujos títulos e palavras-chave apresentassem termos relacionados a: atendimento educacional especializado; denominações de alterações específicas; denominações de professores especializados ou especialistas; professor itinerante; denominações de local do atendimento educacional especializado: classe regular; sala de recurso; sala de recurso multifuncional; classe especial; escola especial; classe hospitalar; análise e/ou procedimentos aplicados ou direcionados ao atendimento educacional especializado.

Critério 41 - Foi realizada leitura dos resumos e estes foram sistematizados em Objetivo/Objeto; Metodologia e Resultados/Conclusão;

Critério 5 - A partir da leitura dos resumos sistematizados, foram elencados temas que formaram 10 categorias a partir do objetivo/objeto referido na pesquisa, sendo: Atendimento educacional especializado (10); Representações Sociais (2); Prática pedagógica (6); Discursos e práticas (1); Ambiente especializado (1); Formação Docente (1); Denominações de 
alterações específicas (5); Programas (4); Concepção de professores sobre inclusão/pessoa com deficiência (1); Competências de profissional qualificado (1); Política educacional e/ou inclusiva; (4). O acervo totaliza 36 teses e dissertações.

Critério 6 - Foi efetuada uma busca pelas dissertações e teses no site da referida Instituição de Ensino Superior - IES que originou a pesquisa. As dissertações e teses que não foram encontradas disponíveis nos referidos sites, foram submetidas a uma busca no site Google acadêmico <http:// scholar.google.com.br». No total, foram encontradas 18 dissertações e teses que compõem a fonte de dados dessa pesquisa. Das 18 dissertações e teses selecionadas, 11 pesquisas são em nível de Mestrado e 07 são em nível de Doutorado. Conforme o período considerado, de 2000 a 2009, a amostragem dessa pesquisa (dissertações e teses) ficou distribuída em ano e quantidade de produção: 2000 (1); 2001 (0); 2002 (1); 2003 (0); 2004 (0); 2005 (2); 2006 (3); 2007 (1); 2008 (3); 2009 (7).

\section{Instrumentos da pesquisa}

O instrumento utilizado para a coleta, organização e análise dos dados foi o Esquema Paradigmático adaptado de Sánchez Gamboa (1987, 2007). Para a realização dessa pesquisa, foram elencados dois níveis (técnico e teórico) e um elemento em separado do nível técnico, ou seja, grau e tipos de mudança proposta. No Nível Técnico, foram analisadas: técnicas de registro; tratamento dos dados (tipo de análise dos dados) e apresentação dos resultados (tipos de procedimentos qualitativos e/ou quantitativos). No Nível Teórico, foram analisados: os principais temas tratados; tipo de abordagem (crítico-dialética; fenomenológico-hermenêutica ou empírico-analítica). Em relação ao Grau e Tipos de mudança proposta foram analisadas: Graus de mudança: Alta e Baixa e Tipos de Mudança: Homeóstasis; Metamorfismo; Incrementalismo ou Neomovilismo.

O Esquema Paradigmático é um instrumento utilizado para a análise da produção científica, proposto por Sánchez Gamboa (1987; 2007). Através do referido esquema, a análise das produções toma um caráter epistemológico, que vai além da análise dos métodos num contexto técnico. O objetivo do autor, ao propor esse instrumento, foi o de "reconstruir a lógica interna, o que ajuda a decifrar e explicar os fundamentos de cada enfoque teórico-metodológico utilizado na pesquisa científica" (SÁNCHEZ GAMBOA, 2007, p. 64).

\section{Resultados e discussões}

\section{Nível técnico}

Foram analisadas: técnicas de registro; tratamento dos dados (tipo de análise dos dados) e apresentação dos resultados (tipos de procedimentos qualitativos e/ou quantitativos). 
Pudemos concluir que o número de pesquisas voltadas ao atendimento educacional especializado é incipiente. Nos anos de 2001, 2003, 2004 não foram encontrados nenhum trabalho referente a esse tema. Mas, o ano de 2009, aparece como sendo o período de maior produção $(n=7)$. Vale considerar que as pesquisas referentes ao atendimento educacional especializado seguem a mesma lógica das produções em Educação Especial, em que o número de pesquisas expressas representam os estudos realizados em Programas de Pós-Graduação de áreas diversificadas, em especial, nos Programas de Psicologia e Educação, em suas áreas correlatas, que vêm contribuindo para a expansão de pesquisas nas áreas de educação especial e, consequentemente, de atendimento educacional especializado (MANZINI, 2009; SILVA; SILVA, 2009).

A maioria das teses e dissertações sobre atendimento educacional especializado foi produzida por Universidades Públicas (72\%) em relação às Universidades Privadas (28\%). Esses números se aproximam dos valores encontrados na pesquisa de Ferreira et al. (2002), que analisaram 81 produções referentes a "Atitudes e percepções acerca dos indivíduos com necessidades educacionais especiais", e verificaram que $80 \%$ delas eram advindas de Universidades públicas, e 20\% de Universidades privadas. Nunes et al. $(2004 ; 2005)$ desenvolveram estudo nas áreas de educação e psicologia voltada a alunos com necessidades educacionais especiais e também verificaram que a maioria das produções ocorreu em Universidades públicas.

Devemos considerar que a expansão do número de Programas de Pós-Graduação e o aumento mesmo que gradativo nos Programas relacionados à Educação Especial não significam, por si só, a melhoria na qualidade das pesquisas nessa área. Em relação ao tipo de pesquisa, as produções em sua maioria não especificam (NE), revelando 44\% ( $\mathrm{n}=8)$ delas. A pesquisa documental aparece com $28 \%(\mathrm{n}=5)$, seguido do estudo de caso com 17 (n=3); pesquisa de campo 5\% (n=1) e Etnografia e cartografia $5 \%(\mathrm{n}=1)$.

As pesquisas analisadas não apresentam uma sistemática na apresentação da metodologia em seus resumos e nos capítulos sobre métodos ou metodologia. Desse modo, deixam de especificar as informações que facilitariam a compreensão do tipo de pesquisa, dos tipos de registros utilizados e do tipo de análise proposto. Esses aspectos aparecem na pesquisa como Não Especificado (NE). Esse resultado revela que as pesquisas em educação especial não possuem seu próprio método de análise, nem uma sistematização no uso de métodos de outras áreas.

Quanto às Técnicas de Registro de Pesquisa, observamos que 50\% (n=9) do total das produções não especificaram; 34\% $(n=6)$ utilizaram a entrevista; questionário $11 \%(n=2)$; entrevista e questionário 5\% ( $n=1)$. A entrevista prevalece como técnica de registro observado também na pesquisa de Manzini (2011).

O tipo de análise de dados não foi especificado por 50\% (n=9) das produções; $28 \%$ (n=5) apresentaram pesquisas do tipo Análise documental. Também apresentaram como tipo de Análise: Análise de conteúdo (n=1) 5,5\%; Metodologia labirín- 
tica (n=1) 5,5\%; Estudo retrospectivo de banco de dados (n=1) 5,5,\% e Delineamento quase experimental (n=1) 5,5\%).

Constatamos a diversificação de enfoques metodológicos relacionados a tipo de pesquisa; técnica de registro de pesquisa e tipo de análise de dados. Essa diversidade na educação especial foi constatada nos trabalhos de Laplane, Lacerda e Kassar (2006). Sabe-se que a educação, inicialmente, preocupava-se com estudos voltados a aspectos psicopedagógicos e psicológicos, muitos deles relacionados a levantamentos estatísticos, mas que vêm, desde 1930, apresentando um aumento na diversidade temática e metodológica (GATTI, 2001). Estudos de Sánchez Gamboa (1987), Silva (2004) e Marques et al. (2008) vêm apontando a concepção empírico-analítica como principal abordagem utilizada nas pesquisas.

Mendes, Nunes e Ferreira (2002), ao analisar as 81 teses e dissertações sobre as "atitudes e percepções acerca dos indivíduos com necessidades educacionais especiais", concluiu, a respeito dos aspectos metodológicos, que $73 \%$ das pesquisas eram descritivas; $23 \%$ era estudo de caso; apenas l estudo era correlacional; um histórico e uma pesquisa-ação. A predominância do aspecto descritivo nas pesquisas em educação especial é destaque nos trabalhos de Mendes et al. (2004); Mendes, Nunes e Ferreira (2004, 2005); Manzini et al. (2006) e Naujorks (2008).

Do total das 18 amostras, $84 \%$ (n=15) apresentaram procedimentos qualitativos, enquanto que $11 \%(\mathrm{n}=2)$ apresentaram procedimentos quantitativos e qualitativos e apenas uma delas $(\mathrm{n}=1)$ apresentou procedimento quantitativo, representando $5 \%$ do total. André (2001), ao analisar a trajetória das pesquisas em educação, mostra que, na década de 1990, houve mudanças nas abordagens metodológicas, momento em que os estudos qualitativos ganharam força.

$\mathrm{Na}$ educação especial, a tendência ao uso de procedimento quantitativo vem sendo superada aos poucos. No estudo de Silva (2004), 87,5\% das pesquisas desenvolvidas na abordagem empírico-analítica, apresentaram abordagem quantitativa, sendo que $45,8 \%$ utilizaram como tipo de pesquisa: a experimental. Podemos considerar o resultado dessa pesquisa como um progresso, em se tratando da maioria das pesquisas ( $84 \%$; $n=15$ ) que fazem uso de procedimento qualitativo, seguido do uso de procedimentos qualitativos e quantitativos com $11 \%(\mathrm{n}=2)$. Corroboramos com o autor Sánchez Gamboa (2003), o qual chama de "falso dualismo" a "falsa opção entre a pesquisa quantitativa e a qualitativa".

Concordamos com o autor no sentido de que o rigor científico, a qualidade da pesquisa e o potencial de mudança não podem ser medidos apenas pelo uso de abordagem qualitativa ou quantitativa. Tanto que, neste estudo, utilizamos ambos os procedimentos, o que tipicamente se caracteriza, segundo Sánchez Gamboa (1987, 2007), como abordagem crítico-dialética.

Conforme os resultados demonstrados, podemos concluir que as pesquisas analisadas apresentam um perfil híbrido na utilização de instrumentos, no uso 
de técnicas de registro, nos instrumentos utilizados, no tipo de análise de dados, demonstrando que não apresentam fronteiras metodológicas, mas apresentam caráter determinante de diversificação metodológica, assim como existência de diferentes tipos de análise de dados que demonstram a heterogeneidade dessas produções.

\section{Nível teórico}

Foram analisados: os principais temas tratados; tipo de abordagem (crítico-dialética; fenomenológico-hermenêutica ou empírico-analítica). Em relação ao Grau e Tipos de mudança proposta foram analisadas: Graus de mudança: Alta e Baixa e Tipos de Mudança: Homeóstasis; Metamorfismo; Incrementalismo ou Neomovilismo.

Em relação aos temas encontrados nas teses e dissertações sobre atendimento educacional especializado, nota-se prevalência na categoria temática "Deficiência Auditiva/Surdez" com 27,7\%, o que não vem ao encontro aos resultados encontrados nas pesquisas em educação especial relacionadas às categorias temáticas já citadas. A categoria "deficiência mental" aparece, porém, em apenas uma amostra.

Marquezine e Tramontina (2006) explicam que Goyos e Dias (1988) e Ferreira (1991) trouxeram contribuições iniciais através de seus trabalhos relacionados à análise da produção científica em educação especial. Esses trabalhos têm, entre outros objetivos, o de compreender quais temas estavam sendo investigados na área.

Ferreira (1991) observou que, dentre as principais áreas temáticas contempladas nos 1.900 trabalhos analisados, destacou-se a "deficiência mental", os "procedimentos de instrução" e "as condições de funcionamento das escolas especiais". Hayashi (2011) destaca Toresan, Reily e Caiado (1995) ao analisar teses e dissertações defendidas em universidades paulistanas, onde concluíram que os temas relacionados à deficiência eram voltados a concepção médica, com foco especialmente para a "deficiência mental".

Mendes (2004), Nunes e Ferreira $(2004 ; 2005)$ também chegaram à conclusão da existência de uma tendência a pesquisa de assuntos específicos, com destaque para a "deficiência mental".

Marquezine e Tramontina (2006), ao analisarem as monografias elaboradas por 143 alunos egressos do Curso de Especialização em Educação - Deficiência Mental da Universidade Estadual de Londrina - UEL, no período de 1987 a 2002, constataram que a categoria "Procedimentos de Ensino na Escola" foi a mais pesquisada. No ano de 2008, Marques et al. concluíram que os temas mais abordados foram: "educação/ensino", e "integração/exclusão", tendo como categoria mais estudada a "deficiência mental", da mesma forma que Mendes et al. (2004) concluíram que os sujeitos das pesquisas eram indivíduos com graus leves de deficiência intelectual. 
Embora exista uma prevalência considerável em diversas pesquisas sobre o tema "deficiência mental", outras pesquisas de produções apontam para a ampliação do foco temático, como a pesquisa de Manzini et al. (2006) ; Jesus e Baptista (2006), citados por Marques et al. (2008); Naujorks (2008).

Concluímos, em relação aos temas, que há uma tendência cada vez maior na diversificação destes, tendo em vista, como já citado, a ampliação dos Programas de Pós-Graduação na área de Educação Especial e as pesquisas de outros Programas voltados a temas correlatos com a educação especial (MANZINI, 2009; SILVA; SILVA, 2009).

A maioria ( $61 \%$ ) das produções apresentou abordagem metodológica que optamos chamar de Inespecífica, devido ao fato de não apresentarem as características, descritas por Sánchez Gamboa $(1987,2007)$, para descrever os aspectos técnico e teórico conforme a proposta do instrumento dessa pesquisa, sendo ele baseado no Esquema Paradigmático do referido autor. A aproximação com a abordagem Fenomenológico-hermenêutica representou 22\% ( $n=4)$ dos resultados, seguido da abordagem Crítico-dialética com 15\% (n=3) e nenhuma produção apresentou aproximação com a abordagem Empírico-analítica.

Nessa análise, verificamos que as pesquisas sobre atendimento educacional especializado não apresentam uma sistemática ou padrão metodológico que possibilite uma verificação mais aprofundada dos tipos de abordagem utilizada. $\mathrm{O}$ resultado inespecífico, referente à aproximação com a abordagem metodológica, pode sugerir que as produções não apresentam uma fronteira metodológica, isto é, não apresentam uma identidade metodológica que diferencie as pesquisas em educação especial de outros tipos de pesquisa, o que pode representar: a) que as áreas que compreendem educação especial, sendo o atendimento educacional uma delas, não vêm apresentando rigor metodológico suficiente para que seja possível a formação de uma identidade metodológica de suas produções; b) que as produções estão demonstrando um avanço no sentido de superar as metodologias empírico-analíticas na área de educação e educação especial, mas, ainda estão passando por uma necessidade de ajuste metodológico que configure as suas tendências metodológicas; c) as produções estão buscando um caminho alternativo que demonstre uma espécie de "liberdade" metodológica.

O resultado dessa pesquisa é diferente dos resultados na pesquisa de Sánchez Gamboa (1987), em que a maioria (66\%) das produções apresentou como principal abordagem a empírico-analítica, assim como a pesquisa de Silva (2004) indicou que a maioria das produções pesquisadas, $88,9 \%$, caracterizaram-se como pesquisas de abordagem empírico-analítica. A pesquisa de Marques et al. (2008) demonstrou como resultado da análise, que 19, das 85 produções analisadas, foram caracterizadas como empírico-analíticas.

Sánchez Gamboa $(1987,2007)$ relacionou características das pesquisas empírico-analíticas aos níveis técnico e teórico. No nível teórico, apresentam técni- 
cas de registro quantitativas, testes padronizados e questionários padronizados. No nível teórico, privilegiam autores clássicos do positivismo e da ciência analítica.

Em relação à aproximação das pesquisas com as abordagens fenomenológico-hermenêuticas, estas compreendem 22\% (n=4). Esses resultados se aproximam da pesquisa de Sánchez Gamboa (1987), em que 22,5\% das produções são fenomenológico-hermenêuticas. Para Silva (2004), 11,1\% do total analisado são fenomenológico -hermenêuticas e para Marques et al. (2008), 57 das 85 pesquisas foram caracterizadas como fenomenológico-hermenêuticas.

Ao nível técnico, as pesquisas de abordagem fenomenológico-hermenêuticas apresentam técnicas de registro não-quantitativas; entrevistas não-estruturadas, relatos de vida, estudos de casos, relatos de experiências. Quanto ao nível teórico, as referências teóricas apresentam a necessidade de definir, de forma ampla, o universo da interpretação e a abertura para a polissemia. Destaca-se a crítica e a necessidade de que a investigação revele e denuncie as ideologias subjacentes ou ocultas, decifre os pressupostos implícitos em discursos, textos, leis, comunicações ou expresse as contradições, conflitos, interesses antagônicos, etc. (SÁNCHEZ GAMBOA, 1987, 2007).

Das 18 teses e dissertações analisadas, $(22 \%$; $n=4)$ delas apresentou aproximações com a abordagem fenomenológico-hermenêutica. Como aspectos em comum, essas produções apresentaram: pesquisas com procedimentos qualitativos; instrumento de análise a entrevista seguida do questionário e presença de crítica voltada à política inclusiva, corroborando com Sánchez Gamboa $(1987,2007)$ em relação as características dos aspectos técnicos e teóricos.

As pesquisas crítico-dialéticas compreenderam $17 \%(\mathrm{n}=3)$ do total das produções. O estudo de Sánchez Gamboa (1987) representa 9,5\% do total, enquanto o trabalho de Silva (2004) revelou que nenhuma produção analisada apresentou características relacionadas a abordagem crítico-analítica. Marques et al. (2008) concluíram que 9 das 85 teses e dissertações analisadas apresentaram tendência crítico-dialética. Podemos notar, com esses resultados, que as pesquisas que apresentam características dialéticas e críticas ou que denotem necessidade de mudanças ou transformações, ainda representam a minoria nas áreas de educação, educação especial e atendimento educacional especializado.

Em nível técnico, as pesquisas classificadas com a abordagem críticodialética utilizam as mesmas técnicas da abordagem fenomenológico-hermenêutica, ou seja, técnicas não qualitativas, como entrevistas não estruturadas, relatos de vida, estudos de casos, relatos de experiências, etc. (SÁNCHEZ GAMBOA, 2007). De modo geral, apresentam a utilização de técnicas quantitativas e qualitativas (leitura dialética); a análise dos dados constitui-se, em geral, de análise documental e análise de conteúdo. No aspecto teórico, segue as mesmas concepções das fenomenológico -hermenêuticas ao que diz respeito a apresentar uma ênfase maior nas referencias teóricas, no entanto, nesse caso, pela "necessidade de assegurar mais informações para 
as análises, contextualizadas a partir de um prévio referencial teórico, fundado no materialismo histórico" (SÁNCHEZ GAMBOA, 2007, p. 86).

Encontramos, nesse estudo, dados que devem ser analisados criticamente pelos pesquisadores em educação especial e atendimento educacional especializado. É importante clarificar as opções metodológicas utilizadas: tipo de pesquisa, instrumentos utilizados para registro de dados, tipo de análise de dados e procedimentos de pesquisa, bem como especificar seu posicionamento em relação a seu objeto ou aos sujeitos analisados. Em relação aos autores, estes devem buscar confrontar os posicionamentos, ao invés de simplesmente citá-los; contextualizar seu posicionamento crítico frente aos fenômenos educativos observados ou analisados, em relação ao panorama da educação, da educação especial e do atendimento educacional especializado, no tocante aos aspectos histórico e políticos ou em relação a outro sistema social, que demonstre sua preocupação em contextualizar sua pesquisa na esfera social e não apenas restringí-la ao lócus da pesquisa.

O tipo de mudança proposta é mais um indicador que pode ser utilizado pra "tipificar as condições e graus de mudança implícitos na tomada de decisão" (SÂNCHEZ GAMBOA, 2007, p. 110). Indica a possibilidade de uma pesquisa reunir a teoria e a prática, a partir da qual poderá apresentar seu potencial de transformação social. Modelos descritivos e estatísticos, por exemplo, oferecem poucas perspectivas de ação e transformação (SÁNCHEZ GAMBOA, 1987).

Conforme as aproximações ${ }^{2}$ das produções com as abordagens metodológicas, essas são reflexo do potencial de mudança proposta por elas. Dessa forma, os resultados apresentados nessa pesquisa nos seguintes resultados: Inespecífica $(61 \%)$; Neomovilismo (22\%); Metamorfose (17\%) e Homeóstase não apresentou nenhum resultado.

A maioria das pesquisas apresentou tipo de mudança que denominamos de Inespecífica, por não se aproximar de nenhuma abordagem especificamente. Isso significa que não podemos aproximar uma pesquisa de nenhuma abordagem metodológica específica e também não podemos aproximar a pesquisa de nenhum tipo específico de mudança proposta. Desse modo, pela proposta de análise epistemológica de Sánchez Gamboa $(1987,2007)$ a maioria das pesquisas não apresenta aproximação com a possibilidade de transformação, embora a maior parte das pesquisas (89\%) apresente crítica, utilize procedimento qualitativo (89\%) e apresente como categoria principal em suas críticas o "distanciamento entre teoria e prática" (n=3) e a "transformação da realidade" (n=2).

O tipo de mudança denominado de Neomovilismo advém da abordagem metodológica fenomenológico-hermenêutica e obteve na pesquisa $22 \%(\mathrm{n}=4)$ do total. No Neomovilismo, o tipo de atividade é inovadora, procurando a invenção, a prova e a definição de soluções para problemas considerados significativos. Tal inovação está baseada em um conhecimento relativamente pequeno, com um volume e exten- 
são de informações reduzidas, mas com grande potencial de mudanças, motivada por uma proposta de nova visão, de novos sentidos, com ênfase a organização diferenciada de informações já existentes.

Metamorfose é a denominação dada a tipos de mudança proposta relacionada a abordagem metodológica crítico-dialética, representando, nessa pesquisa, 17\% do total. Sánchez Gamboa (2007, p. 113) explica que: entre abordagens crítico-dialéticas estão as "propostas de transformações "utópicas" desejando mudanças fundamentais no fenômeno estudado. As pesquisas que apresentam críticas possuem uma maior possibilidade de promoverem mudanças ou transformações. Mas não significa que as abordagens empírico-analíticas não sejam capazes de promover essas mudanças ou transformações.

Em se tratando de uma discussão voltada aos tipos de abordagem metodológica nas ciências humanas, em especial na educação e na educação especial, constatamos que há uma busca pelo que André (2001) chama de rigor científico e pela qualidade das pesquisas. Se considerarmos o potencial de mudança promovido pelas pesquisas, nas diversas áreas e pela contribuição que vêm trazendo à humanidade, temos que assegurar que as mudanças ocorridas nos referenciais e nas metodologias realmente se efetivem em forma de pesquisas de qualidade que possam significar mudanças e transformações para melhor. Essas transformações a que nos referimos dizem respeito àquelas ocorridas no decorrer do processo da pesquisa, durante sua realização e após sua conclusão, significando que pode ampliar sua possibilidade de mudança para a comunidade e para a sociedade.

Em relação aos resultados do nível técnico, verificamos a diversidade metodológica e temática presente nas produções. Pudemos notar a diversidade metodológica em relação aos tipos de pesquisa, às técnicas de registro e em relação o tipo de análise dos dados. Notamos que, em relação ao procedimento de pesquisa, houve um avanço no aspecto qualitativo, se compararmos a resultados de pesquisas (SÁNCHEZ GAMBOA, 1987; SILVA, 2004) que obtiveram como resultado a predominância da abordagem a empírico-analítica, o que significa uso de padrão metodológico quantitativo. As produções analisadas demonstram uma preocupação com o tratamento qualitativo, mesmo quando são utilizados dados quantitativos. Consideramos que está havendo um avanço nas pesquisas em educação especial se compararmos os resultados de pesquisas que mostram o perfil descritivo predominante nas produções (MENDES; NUNES; FERREIRA, 2002, 2004, 2005; MENDES et al., 2004; MANZINI, 2006; NAUJORKS, 2008; entre outros).

Compreendemos que pesquisas do tipo descritivas se constituem como importantes ferramentas, se consideradas como forma inicial de pesquisa ou como complemento para enriquecer a metodologia utilizada, a fim de atingir os objetivos desejados. A análise do nível teórico permitiu inferir sobre a diversidade temática, a presença do aspecto crítico, bem como as concepções acerca dos fenômenos educativos e sua relação com as abordagens metodológicas. A diversidade temática pode estar relacionada, entre outros motivos, à amplitude de temas tratados pela educação especial e pelo atendimento educacional especializado, em relação, por exemplo, à 
clientela do atendimento, aos tipos de deficiências ou a habilidades especiais, à diversidade de profissões envolvidas, a instrumentos utilizados, enfim, ao que permite o uso de uma gama de temas para realização de pesquisas. Importante destacar, em relação aos temas tratados, a ampliação de temas antes voltados predominantemente à deficiência mental.

\section{Conclusão}

A maioria das pesquisas sobre atendimento educacional especializado apresentam uma característica que chamamos de caráter híbrido, ou seja, não é possível estabelecer características que possibilitem enquadrar as pesquisas dentro de uma abordagem metodológica específica, já que não apresentam fronteira metodológica. Sobre isso, elencamos algumas hipóteses que talvez possam se aproximar de uma resposta para esse hibridismo metodológico: a) que as áreas que compreendem educação especial, sendo o atendimento educacional uma delas, não vêm apresentando rigor metodológico suficiente para que seja possível a formação de uma identidade metodológica de suas produções; b) que as produções estão demonstrando um avanço no sentido de superar as metodologias empírico-analíticas na área de educação e educação especial, mas ainda estão passando por uma necessidade de ajuste metodológico que configure as suas tendências metodológicas; c) as produções não estão se atendo a fronteiras metodológicas pré-estabelecidas e estão buscando um caminho alternativo que demonstre uma espécie de "liberdade" metodológica.

Destacamos que os resultados referentes aos achados que caracterizam as pesquisas de abordagem metodológica fenomenológico-hermenêutica e críticodialética, representam um avanço significativo no fazer pesquisa sobre atendimento educacional especializado, já que possuem, como características principais, o uso de procedimentos qualitativos e a presença de crítica, o que contribui para desvelar e reinterpretar discursos e buscar a transformação. A transformação no sentido da superação do "moralismo abstrato" (PLAINSEANCE, 2004) condiciona muitos a cristalizarem as suas ações e a aceitarem as proposições políticas em forma de discursos românticos e impraticáveis.

É de suma importância que sejam ampliadas as pesquisas sobre análise epistemológica, a fim de que se estabeleçam resultados que possam fomentar as discussões nessa área, para que possamos contribuir de forma significativa para a melhoria na qualidade das pesquisas e para sua aproximação com a práxis.

\section{Referências}

ANDRÉ, M. Pesquisa em educação: buscando rigor e qualidade. Cadernos de Pesquisa, São Paulo, n. 113, p. 51-64, jul. 2001. Disponível em: 〈http://www.scielo.br/pdf/cp/nll3/a03nll3.pdf〉. Acesso em: 21 nov. 2010.

ARAÓZ, S. M. M. Inclusão de alunos com deficiência múltipla: análise de um programa de apoio. 2009, 185 f. Tese (Doutorado em Educação Especial) - Universidade Federal de São Carlos, São Carlos, 2009.

BARDIN, L. Análise do conteúdo. Ed. ver. e aum. Lisboa: Edições 70, 2009. 
BRASIL. Ministério da Educação. Declaração Mundial sobre Educação para Todos (Conferência de Jomtien - 1990). Plano de ação para satisfazer as necessidades básicas de aprendizagem. Disponível em: 〈http://www.dominiopublico.gov.br/download/texto/ue000108.pdf〉. Acesso em 08 nov. 2010.

CHIESA, M. Implantação do atendimento educacional especializado na rede municipal de ensino de pelotas sob a perspectiva da educação ambiental. 2009, 112 f. Dissertação de Mestrado (Mestrado em Educação Ambiental) - Universidade Federal do Rio Grande, Rio Grande, 2009.

DIAS, M. C. Atendimento educacional especializado complementar e a deficiência intelectual: considerações sobre a efetivação do direito à educação. 2010, 156 f. Dissertação (Mestrado em Educação) - Universidade de São Paulo, São Paulo, 2010.

FERREIRA, J. R. Pesquisa no contexto da política em educação especial. In: SEMINÁRIO BRASILEIRO DE PESQUISA EM EDUCAÇÃO ESPECIAL, 2., 1991, Rio de Janeiro. Anais... Rio de Janeiro: UFRJ, 1991. p. $8-11$.

FERREIRA, J. R.; SOUZA, M. I.; NUNES, L. R. O. P.; MENDES, E. G.; GLAT, R. Teses e dissertações de educação e psicologia: formação de recursos humanos para educação especial. Temas em Psicologia, Ribeirão Preto, v. 10, n. 3, 2002

GATTI, B. A. Pós-graduação e pesquisa em educação no Brasil, 1978-1981. Cadernos de Pesquisa, São Paulo, n. 44, p. 3-17, fev., 1983.

Implicações e perspectivas da pesquisa educacional no Brasil contemporâneo. Cadernos de Pesquisa, São Paulo, n. 113, p. 65-81, jul. 2001.

HAYASHI, M. C. P. I. Múltiplos olhares sobre a produção do conhecimento em educação especial. Revista Diálogo Educacional, Curitiba, v. 11, n. 32, p. 145-165, jan./abr. 2011.

A educação do deficiente no Brasil: dos primórdios ao início do século XXI. 2. ed. Campinas: Autores Associados, 2006.

LAPLANE, A. L. F.; LACERDA, C. B. F.; KASSAR, M. C. M. Abordagem qualitativa de pesquisa em educação especial: contribuições da etnografia. In: REUNIÃO DA ANUAL DA ANPED, 29., 2006, Caxambu. Anais... Caxambu, 2006.

LÜDKE, M; ANDRÉ, M. E. D. A. Pesquisa em educação: abordagens qualitativas. São Paulo, EPU, 1986.

MAGALHÃES, M. G. M. S. Programa de atendimento ao superdotado da Secretaria de Estado da Educação do Distrito Federal (1991-1992): inclusão social ou tergiversação burocrática? 2006, 394 f. Tese (Doutorado em Sociologia) - Universidade de Brasília, Brasília, 2006.

MANZINI, E. J.; Introdução. In: MARQUEZINE, M. C.; MANZINI, E. J.; TANAKA, E. D. O.; FUJISAWA, D. S.; BUSTO, R. M. (Orgs.). Tópicos de metodologia para educação especial. Londrina: ABPEE, 2009. p. $1-7$.

MANZINI, E. J.; PAULINO, V. C.; CORRÊA, P. M.; SILVA, M. O.; LOPES, N. A. C. Análise de dissertações e teses em educação especial produzidas no Programa de Pós-Graduação em Educação da UNESP - Marília (1993-2004). Revista Educação Especial, Santa Maria, n. 28, 2006. Disponível em: ‘http://coralx.ufsm.br/ revce/ceesp/2006/02/al4.htm>. Acesso em: 15 mar. 2011.

MARQUES, L. P.; CARNEIRO, C. T.; ANDRADE, J. S.; MARTINS, N. T.; GONÇALVES, R. M. Analisando as pesquisas em educação especial no Brasil. Revista Brasileira de Educação Especial, Marília, v. 14, n. 2, p. 251-272, maio/ago. 2008. 
MARQUEZINE, M. C.; TRAMONTINA, V. M. Produção científica dos alunos egressos do curso de especialização da Universidade Estadual de Londrina. Revista Brasileira de Educação Especial, Marília, v. 12, n. 1, p. 101-122, jan./abr. 2006.

Educação Especial no Brasil: História e políticas públicas. São Paulo: Cortez, 1996.

MENDES, E. G.; NUNES, L. R. O. P.; FERREIRA, J. R. Atitudes e percepções acerca dos indivíduos com necessidades educacionais especiais. Temas em Psicologia, Rio de Janeiro, v. 10, n. 2, p. 121-134, mar. 2002.

MENDES, E. G.; NUNES, L. R. O. P.; FERREIRA, J. R.; SILVEIRA, L. C. Estado da arte das pesquisas sobre profissionalização do portador de deficiência. Temas em Psicologia, Rio de Janeiro, v. 12, n. 2, p. 105-118, 2004.

NAUJORKS, M. I. Análise preliminar da pesquisa em educação especial e inclusão educacional na ANPED Sul. Revista Educação Especial, Santa Maria, n. 32. p. 301-308, 2008. Disponível em: ‘http://cascavel.ufsm. br/revistas/ojs.2.2.2/index.php/educacaoespecial/article/viewFile/105/78>. Acesso em: 25 maio 2011.

NUNES, L.R. O.P.; FERREIRA, J.R.; MENDES, E.G. Produção discente da pós-graduação em educação e psicologia sobre o indivíduo com necessidades educacionais especiais. In: MENDES, E. G.; ALMEIDA, M. A.; WILLIAMS, L. C. A.(Orgs.). Temas em educação especial: avanços recentes. São Carlos: EdUFSCar, 2004. p. 131-142.

O conhecimento produzido nos programas de pós-graduação sobre a educação da pessoa com necessidades especiais. In: ENCONTRO DE PESQUISA EM EDUCAÇÃO DA REGIÃO SUDESTE, 7., 2005, Belo Horizonte. Anais... Belo Horizonte: ANPEd-Fórum Região Sudeste, 2005. CD ROM.

QUEIROZ JUNIOR, E. de. Formação continuada de professores para o atendimento educacional especializado: desafios e perspectivas. 2010, 117 f. Dissertação (Mestrado em Educação) - Faculdade de Educação, Universidade de São Paulo, São Paulo, 2010.

SÁNCHEZ GAMBOA, S. A. Epistemologia da pesquisa em educação: estruturas lógicas e tendências metodológicas. 1987, 229 f. Tese (Doutorado em Educação - Filosofia e História da Educação) - Faculdade de Educação, Universidade Estadual de Campinas, Campinas, 1987.

Pesquisa qualitativa: superando tecnicismos e falsos dualismos. Revista Contrapontos, Itajaí, v. 3, n. 3, p. 393-405, set./dez. 2003

Pesquisa em Educação: métodos e epistemologias. Chapecó: Argos, 2007.

SILVA, M. F. N. Encaminhamento de alunos para sala de recursos: análise sobre os argumentos apresentados pelos professores de classes comuns. 2010, 141 f. Dissertação (Mestrado em Educação) - Faculdade de Educação, Universidade de São Paulo, São Paulo, 2010.

SILVA, R. G. O professor especialista da sala de recursos multifuncionais e a qualidade na educação infantil: uma aproximação possível. 2008, 195 f. Dissertação (Mestrado em Educação) - Universidade de Brasília, 2008.

SILVA, R. H. R.; SILVA, S. M. F. M. Processo de criação e expansão da pós-graduação Stricto-Sensu em educação/educação especial no Brasil. In: MARQUEZINE et al. Tópicos de metodologia de pesquisa para educação especial. Londrina: ABPEE, 2009. p. 15-23.

SILVA. R. H. R. Análise epistemológica das dissertações e teses defendidas no programa de pós-graduação em educação especial da UFSCar: 1981-2002. 2004, 193 f. Dissertação (Mestrado em Educação Especial) - Universidade Federal de São Carlos, São Carlos, 2004. 


\section{Correspondência}

Gilmar de Carvalho Cruz - Universidade Estadual do Centro-Oeste, Setor de Ciências da Saúde / Departamento de Educação Física. PR 153 - Km 07, Riozinho, CEP: 84500-000 - Irati, Paraná - Brasil. Caixa-postal: 21

E-mail: rosanaccasagrande@hotmail.com-gilmar@irati.unicentro.br

Recebido em 01 de janeiro de 2013

Aprovado em 22 de maio de 2013 